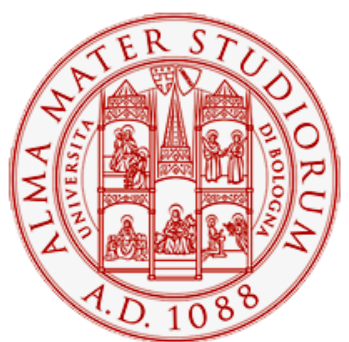

Alma Mater Studiorum - Università di Bologna DEPARTMENT OF ECONOMICS

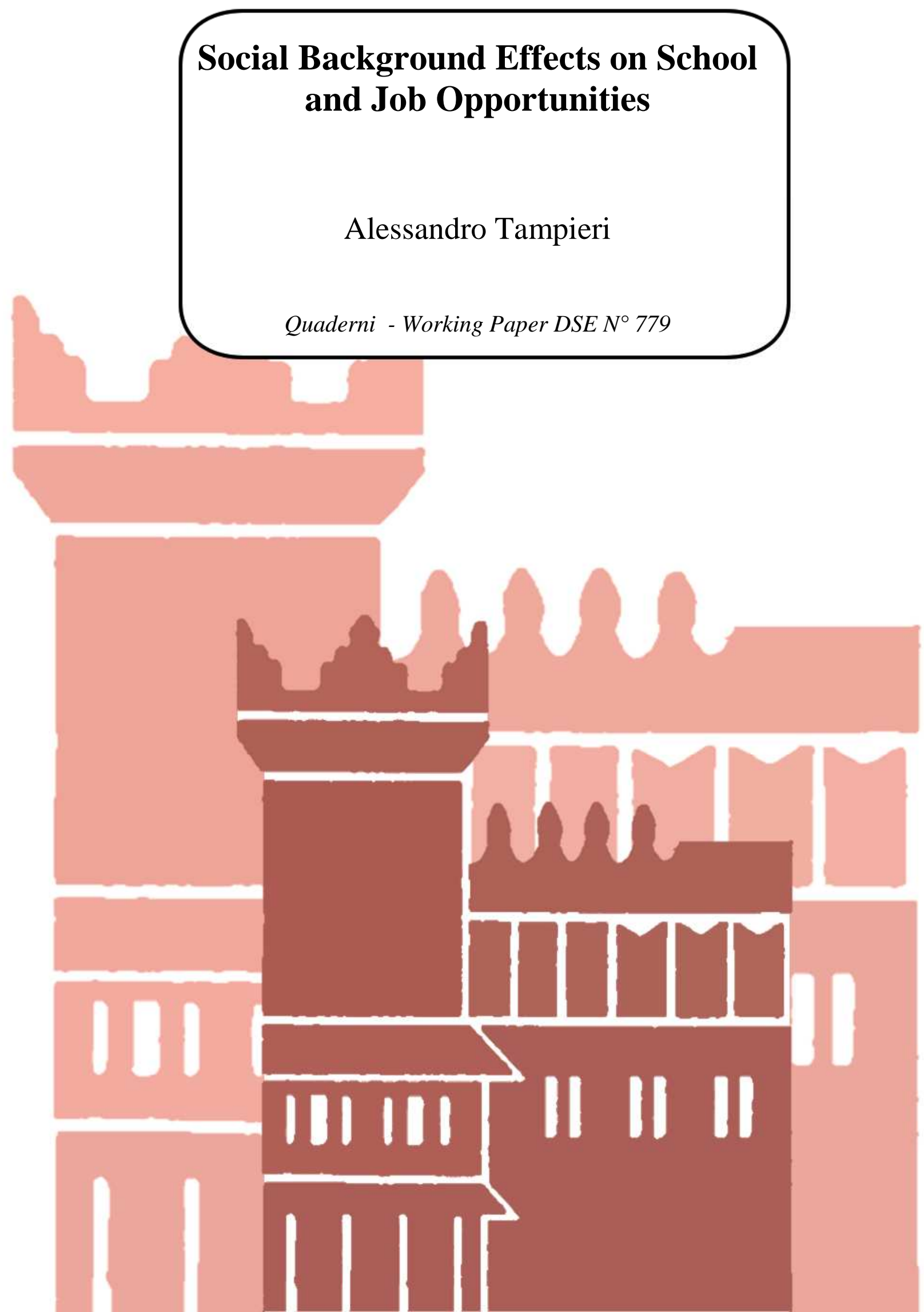




\title{
Social Background Effects on School and Job Opportunities*
}

\author{
Alessandro Tampieri ${ }^{\dagger}$ \\ University of Bologna \\ September 1, 2011
}

\begin{abstract}
This paper proposes a theory on how students' social background affects their school attainment and job opportunities. We study a setup where students differ in ability and social background, and we analyse the interaction between a school and an employer. Students with disadvantaged background are penalised compared to other students: they receive less teaching and/or are less likely to be hired. A surprising result is that policy aiming to subsidise education for disadvantaged students might in fact decrease their job opportunities.
\end{abstract}

JEL Numbers: C73, I21, J24; Keywords: Social background, Ability.

${ }^{*}$ I would like to thank Tom Allen, Giorgio Brunello, Carlos Carrillo-Tudela, Gianni De Fraja, Vincenzo Denicolò, Gaia Garino, Marianne Haraldsvik, Andrea Ichino, Matteo Lippi Bruni, Miltos Makris, Suresh Mutuswami, Piero Pasotti, Joanna Poyago-Theotoky, Ludovic Renou, Johan Rewilak, Javier Rivas, Richard Romano and Piercarlo Zanchettin for many suggestions that have led to substantial improvement on previous drafts. Earlier versions of this paper has been presented to the Royal Economic Society PhD meeting, London 2011, the Summer School in Public Economics, Barcelona 2010, the Scottish Economic Society Annual Conference, Perth 2009 and to seminars in Leicester, Lancaster, Konstanz and Goettingen, 2010 and Bank of Italy, Rome 2009, where I received helpful comments. The usual disclaimer applies.

${ }^{\dagger}$ University of Bologna, Department of Economics, Strada Maggiore 45, Bologna 40125 Italy. 


\section{Introduction}

There is substantial evidence that individuals' social background influences their educational results and job opportunities ${ }^{1}$. This paper proposes a theoretical explanation for this by examining how school and employer behaviour changes according to the students' social background.

We consider a signalling game between a school and an employer where the students they deal with differ in ability and social background. The school prepares students for a final exam and wants the largest number of them to be hired. We assume that teaching improves the students' chance of obtaining a good grade but not their ability. On the other side, the employer wants to hire only high-ability students and observes the exam grade as a signal of ability.

We assume that students with advantaged social backgrounds are more likely to have higher ability. This assumption is crucial for our results and is supported by past research documenting that family and environmental factors are major predictors of cognitive skills (Cunha et al., 2006, Carneiro and Heckman, 2003, Joshi and McCulloc, 2000). The idea is that given the same distribution of innate ability within populations with differing social backgrounds, an advantaged environment can help develop skills via parental and peer pressure.

Our results suggest that students from a disadvantaged social background receive less teaching and/or are hired with less chance. The intuition is the following. The employer prefers advantaged rather than disadvantaged and high-grade students as they are more likely to have high ability. To increase the hiring opportunities of disadvantaged students, the school may devote less

\footnotetext{
${ }^{1}$ For some empirical evidence on the relationship between social background and educational attainment, see Haveman and Wolfe (1995) for a discussion, while Galindo-Rueda and Vignoles (2005) and Marcenaro-Gutierrez et al. (2007) give some recent contributions. For job opportunities, Glyn and Salverda (2000) and Berthoud and Blekesaune (2006) show how social background affects the chance of finding a job in OECD countries and UK, respectively.
} 
teaching effort to disadvantaged and low-ability students, because this gives them less chance of obtaining a high grade, and thus the expected ability of disadvantaged and high-grade students increases. Despite that, the employer may still find it preferable to hire advantaged students. Thus disadvantaged students are penalised in school attainment and/or in job opportunities, and this clearly aggravates class differences.

Furthermore, these results are related to the phenomenon known as grade inflation, which takes place when good grades are awarded too easily. An interesting result is that the presence of grade inflation might help disadvantaged students to have the same job opportunities as advantaged students. The reason is that grade inflation diminishes the employer's expectations about students' ability. Since the school here devotes less teaching effort to disadvantaged rather than advantaged and low-ability students, the effect of grade inflation is relatively stronger for advantaged students. This leads high-grade students to have the same job opportunities irrespective of their social backgrounds.

We then consider a government that subsidises the cost of teaching disadvantaged students. Such policy may diminish their chance of being hired. The reason is that more low-ability and disadvantaged students obtain a high grade, therefore the employer's expectations about the ability high-grade and disadvantaged students decrease.

The paper can be related to the literature on signalling models (Spence, 1973; for a survey of the literature, see Riley, 2001). In particular, the model presents a structure which is similar to Waldmann (1984), where a game between an employer and the job market takes place and the employees are "no players". In analogy, in our model a school and an employer interact and the students are "no players".

The paper is also related to the literature on grade inflation. Chan et al. (2007) propose a signalling model where employers know only the students' grade but not the students' ability and the state of the world (that is, the 
proportion of talented students). This gives rise to an incentive to help some low ability students by giving them good grades. Indeed the labour market cannot fully distinguish whether this is due to a high grading standard or whether the school has a large proportion of talented students, and this in turn hampers the signal of good students. In Chan et al. differences in social background are not considered, which instead are central in our analysis. Also, we assume that the employer knows the proportion of talented students.

Schwager (2008) examines the impact of grade inflation on the job market with students that differ in ability and social background. They are matched with firms which offer different kinds of job, according to the grade and the expected ability. Regardless of the social background, it is possible that mediocre students receive a high grade caused by grade inflation. Also, the high-ability students from advantaged backgrounds may benefit from grade inflation since this shields them from the competition on the part of able and disadvantaged students. Compared to this analysis, we share the same assumptions on the distributions of ability with differing social backgrounds, but in our model disadvantaged students may benefit from the presence of inflation grade.

Finally, our paper is related to De Fraja (2005) who studies the provision of education when students differ in ability and social background. In the presence of asymmetric information (the government does not know the student's ability) and externalities (the public provision of education makes students acquire more education than they would acquire privately) the optimal provision of education is a second best result where high-ability and disadvantaged students receive more education than high-ability and advantaged students. Hence the introduction of reverse discrimination policies, like affirmative action ${ }^{2}$, are justified on efficiency grounds, and the trade-off

\footnotetext{
${ }^{2}$ The term "affirmative action" refers to policies that attempt to increase the presence of individuals who belong to minorities in areas of employment and education. These policies generate controversy when they involve preferential selection on the basis of race, gender or ethnicity.
} 
between equity and efficiency disappears. According to our results, a policy intervention is necessary in order to obtain the optimal provision of education in the presence of differences in social background, since a school caring about the employment of its students does not devote more teaching effort to disadvantaged rather than advantaged and high-ability students.

The remainder of the paper is organised as follows. The model is presented in Section 1.2. Section 1.3 examines the equilibria. Section 1.4 considers the government intervention. Section 1.5 concludes.

\section{The model}

We study the interaction between a single school and a single employer. ${ }^{3}$ The interaction takes place since a number of students, with measure normalised to one, attends school and afterwards asks the employer for a job.

Students can have high $\left(\theta_{H}\right)$ or low $\left(\theta_{L}\right)$ ability. In addition to ability, students can come from advantaged $(a)$ or disadvantaged $(d)$ social backgrounds, which is public information: this can be interpreted as a one-dimensional measure of family environment, peer groups ${ }^{4}$ and neighbourhood. We denote as $\lambda \in[0,1]$ the proportion of advantaged students. Let $p_{a}, p_{d} \in[0,1]$ be the probability that an advantaged or disadvantaged student has highability, respectively. As we stressed in the introduction, we assume $p_{a}>p_{d}$.

\footnotetext{
${ }^{3}$ For simplicity, we abstract from factors such as competition between schools and between employers.

${ }^{4}$ Peer groups means that students learn better if they are in a group of abler students. See Moreland and Levine (1992) for a psychology viewpoint, Summers and Wolfe (1977), Henderson et al. (1978), Epple et al. (2003) and Zimmer and Toma (2000) for economic empirical studies. From a theoretical point of view, see Arnott and Rowse (1987), de Bartolome (1990) and Epple and Romano (1998) that consider explicitly the peer group effect.
} 


\section{$2.1 \quad$ Employer}

The employer decides whether or not to hire a student and offers a single job type.

We define job capacity as the maximum number of students that may be hired and we denoted it as $\Phi \in[0,1]$. For the sake of simplicity, we assume that $\Phi$ is exogenous and depends on the employer's production potential, that is the size and technology of his firm. As a consequence, neither the interaction between school and the employer nor the students' type can affect the employer's production potential.

Still for simplicity, we rule out uncertainty in the market where the employer operates and we assume that the students' ability determines the employer's profit entirely. In particular, each high-ability student yields a profit of $\nu>0$ while each low-ability student yields a profit of -1 . The choice of $\nu$ and -1 is to simplify the algebra: other normalisations would complicate the analysis without changing the results. The assumption that a low-ability student gives negative profit can be interpreted in many ways: low-ability employees may have a marginal productivity which is lower than salary cost. In addition, the employer may want to lay off a low-ability employee but this action still comes at a cost, e.g. industrial disputes, wasted training costs and time, and so on. Thus the employer's payoff is given by $\nu H\left(\theta_{H}\right)-H\left(\theta_{L}\right)$, where $H\left(\theta_{H}\right)$ and $H\left(\theta_{L}\right)$ are the number of hired students with high or low ability, respectively.

The employer doesn't know the students' ability and observes the grade that a student obtains in a final exam ${ }^{5}$ as a signal of it. The possible exam outcomes are a low $\left(g_{D}\right)$ or a high $\left(g_{U}\right)$ grade.

\footnotetext{
${ }^{5}$ The exams which we have in mind in the real world are the "Scholastic Assessment Test" in United States and the "National Curriculum Assessment" in United Kingdom. These exams are managed by the "Educational Testing Service" (Rourke and Ingram, 1991).
} 


\subsection{School}

The school influences job opportunities by preparing students for the final $\operatorname{exam}^{6}$, and learns the students' ability through their tests and assessments results.

The school obtains a benefit $\mu>0$ for every hired student. The reason is that each student's employment increases its reputation as an effective institution for obtaining a job. Of course a school might pursue this objective in different ways, for example, by having a preference for some of their students: it may derive more benefit from increases in the job opportunities of their brightest pupils, or, vice versa, from increases in the job opportunities of their weakest pupils. To depict the interaction with the employer in the most general way we abstract from these differences.

The preparation for the exam requires resources: the quantity of teaching, the quality of buildings and classroom equipment and the teachers' effort. We refer to all these aspects as "teaching". In addition to teaching, the school can provide some students with "extra teaching", that is additional resources, extra tuition, trips and more facilities. We assume that, with teaching only, the student's probability of obtaining a high grade is $\eta_{H} \in(0,1)$ if she has high ability and zero if she has low ability. With extra teaching, the student's probability of obtaining a high grade is 1 if she has high ability and $\eta_{L} \in(0,1)$ if she has low ability. The school bears a cost $c>0$ for each student receiving extra teaching.

Hence the school's payoff is given by $\mu\left(H\left(\theta_{H}\right)+H\left(\theta_{L}\right)\right)-c E T$, where $E T$ is the number of students receiving extra teaching.

\footnotetext{
${ }^{6}$ Note that the school does not arrange the exam and hence it cannot manipulate the students' grades.
} 


\subsection{The game between the school and the employer}

The interaction can be described as follows. Nature draws the student types. Then, each student ${ }^{7}$ attends school and the school chooses whether to give her extra teaching. At the end of school period, students take the final exam. Finally, each student applies for a job, and the employer decides whether to hire her.

\section{Equilibria}

We study the perfect Bayesian equilibria of this game. The choice of this equilibrium concept is motivated by the employer's missing information about students' ability.

A perfect Bayesian equilibrium is a combination of school and employer strategies and beliefs where both agents maximise their payoff. After observing a grade, the employer has a belief about the student type, conditional on all the information he has: student's grade, distribution of ability according to the student's social background and school strategy. Hence his belief must be consistent with Bayes' rule. For each grade, the employer must maximise his expected profit, given his belief and the school strategy. In turn the school's strategy must maximise its expected payoff, given the employer's strategy $^{8}$. Then, job capacity requires that the number of hired students is at most $\Phi$.

We start by making the following assumptions.

Assumption $\left.1 \Phi<\lambda\left(p_{a}+\eta_{L}\left(1-p_{a}\right)\right)+(1-\lambda)\left(p_{d}+\eta_{L}\left(1-p_{d}\right)\right)\right)$.

Assumption $2 \mu>\max \left\{\frac{c}{\eta_{L}}, \frac{c}{1-\eta_{L}}, \frac{c}{\eta_{H}}, \frac{c}{1-\eta_{H}}\right\}$.

\footnotetext{
${ }^{7}$ For simplicity, we assumed away the influence of student's effort.

${ }^{8}$ Note that the school has perfect information of the student types.
} 
Assumption 1 says that job capacity is lower than the highest possible number of high-grade students. This assumption focuses the attention on the equilibria where social background plays a role in the school and employer's decisions. When this assumption does not hold, the employer may hire all the high-grade students irrespective of their social background. In other words, the individuals' social background would not affect their job opportunities. As we stressed in the introduction, the empirical evidence tells us in reality this is not the case, so we prefer to set this case aside.

Assumption 2 says that the school benefit of having a hired student is sufficiently higher than the cost of providing her with extra teaching. This rules out the possibility that a student would not receive extra teaching because, according to the school technology, it is too costly. Here we want to focus on the case where the school's response depends on the employer strategy completely, and disregard the role of school technology ${ }^{9}$. After presenting Assumption 1 and 2, we introduce the notations of the school and employer's actions:

- $x_{L a}, x_{H a}, x_{L d}, x_{H d} \in[0,1]$ are the probabilities that the school gives extra teaching to an advantaged and low or high-ability student and to a disadvantaged and low or high-ability student, respectively;

- $z_{U a}, z_{D a}, z_{U d}, z_{D d} \in[0,1]$ are the probabilities that the employer hires an advantaged student with a high or low grade and a disadvantaged student with a high or low grade, respectively.

We then define the employer beliefs about the students ability. These are denoted by $\pi\left(\theta_{z} \mid g_{j}, p_{i}, x_{z i}\right)$, where $z \in\{H, L\}$ is the ability level, $g_{j}, j \in$ $\{U, D\}$ is the grade, $p_{i}, i \in\{a, d\}$ is the distribution of ability and $x_{z i}$ is the school strategy.

\footnotetext{
${ }^{9}$ To relax this assumption would allow us to compare schools with different technology. This investigation can be interesting and may be considered for future work.
} 
Definition 1 The employer's beliefs about the students' ability which are consistent with the Bayes' rule are

$$
\pi\left(\theta_{H} \mid g_{j}, p_{i}, x_{H i}\right)=\frac{p_{i} x_{H i}}{p_{i} x_{H i}+\eta_{L} x_{L i}\left(1-p_{i}\right)},
$$

and

$$
\pi\left(\theta_{L} \mid g_{j}, p_{i}, x_{L i}\right)=\frac{\eta_{L} x_{L i}\left(1-p_{i}\right)}{p_{i} x_{H i}+\eta_{L} x_{L i}\left(1-p_{i}\right)} .
$$

As we will show below in the proof of Proposition 2, if Assumption 1 and 2 hold the equilibrium will be one of three types, which we label highemployment, middle-employment and low-employment equilibrium.

Definition 2 A high-employment equilibrium is an equilibrium in which the school strategy is $x_{H a}=x_{H d}=x_{L a}=x_{L d}=1$, while the employer strategy is

$$
z_{U a}=1, z_{U d}=\frac{\Phi-\lambda\left(p_{a}+\eta_{L}\left(1-p_{a}\right)\right)}{(1-\lambda)\left(p_{d}+\eta_{L}\left(1-p_{d}\right)\right)} \in(0,1), z_{D a}=z_{D d}=0 .
$$

Definition 3 A middle-employment equilibrium is an equilibrium in which the school strategy is $x_{H a}=x_{H d}=x_{L a}=1, x_{L d}=p_{d} \nu /\left(1-p_{d}\right) \eta_{L} \in(0,1)$, while the employer strategy is

$z_{U a}=1, z_{U d}=\min \left\{\frac{c}{\mu \eta_{L}}, \frac{\Phi-\lambda\left(p_{a}+\eta_{L}\left(1-p_{a}\right)\right)}{(1-\lambda)\left(p_{d}(1+\nu)\right)}\right\} \in(0,1), z_{D a}=z_{D d}=0$.

Definition 4 A low-employment equilibrium is an equilibrium in which the school strategy is $x_{H a}=x_{H d}=1, x_{L a}=p_{a} \nu /\left(1-p_{a}\right) \eta_{L} \in(0,1), x_{L d}=$ $p_{d} \nu /\left(1-p_{d}\right) \eta_{L} \in(0,1)$, while the employer strategy is

$$
z_{U a}=z_{U d}=\min \left\{\frac{c}{\mu \eta_{L}}, \frac{\Phi}{\left(\lambda p_{a}+(1-\lambda) p_{d}\right)(1+\nu)}\right\} \in(0,1), z_{D a}=z_{D d}=0 .
$$

In the high-employment equilibrium the employer hires $\Phi$ students (i.e., as many students as he can according to job capacity) while the school pro- 
vides every student with extra teaching. Here the employer obtains a positive expected profit from high-grade students from both advantaged and disadvantaged backgrounds. Thus, his optimal strategy is to hire all of them, but Assumption 1 prevents this possibility. Then the employer needs to choose between these two types. He will hire all the advantaged students, since they give a higher expected profit, and the disadvantaged students will be hired only for the remaining job capacity.

In the middle-employment equilibrium, the employer does not want to hire all the disadvantaged and high-grade students ${ }^{10}$. In turn, the school provides extra teaching to a lower number of disadvantaged and low-ability students. This strategy increases the probability that a disadvantaged and high-grade student has high ability and thus it increases her chance to be hired.

In the low-employment equilibrium, the employer does not hire all the high-grade students from both advantaged and disadvantaged backgrounds, but is indifferent between hiring one of these two types. Like in the previous equilibrium, the school provides extra teaching to fewer disadvantaged than advantaged and low-ability students.

Note that the employer never hires a low-grade student: indeed all the high-ability students receive extra-teaching in each equilibrium, thus a lowgrade student has low ability with probability one.

\subsection{General case: differences in social background}

In this section, we consider $\lambda \in(0,1)$. The following proposition shows which equilibrium occurs depending on the values of $p_{d}$ and $p_{a}$.

Proposition 1 Let Assumptions 1 and 2 hold. The high-employment equilibrium occurs if $p_{a} \geq p_{d} \geq \eta_{L} /\left(\nu+\eta_{L}\right)$; the middle-employment equilibrium occurs if $p_{a} \geq \eta_{L} /\left(\nu+\eta_{L}\right)>p_{d}$; the low-employment equilibrium occurs if $p_{d}<p_{a}<\eta_{L} /\left(\nu+\eta_{L}\right)$.

\footnotetext{
${ }^{10}$ Given this strategy, the total of hired students might be higher or lower than job capacity, and in the former case clearly this is $\Phi$ again.
} 
Proof. See Appendix.

Figure 1. Differences in social background

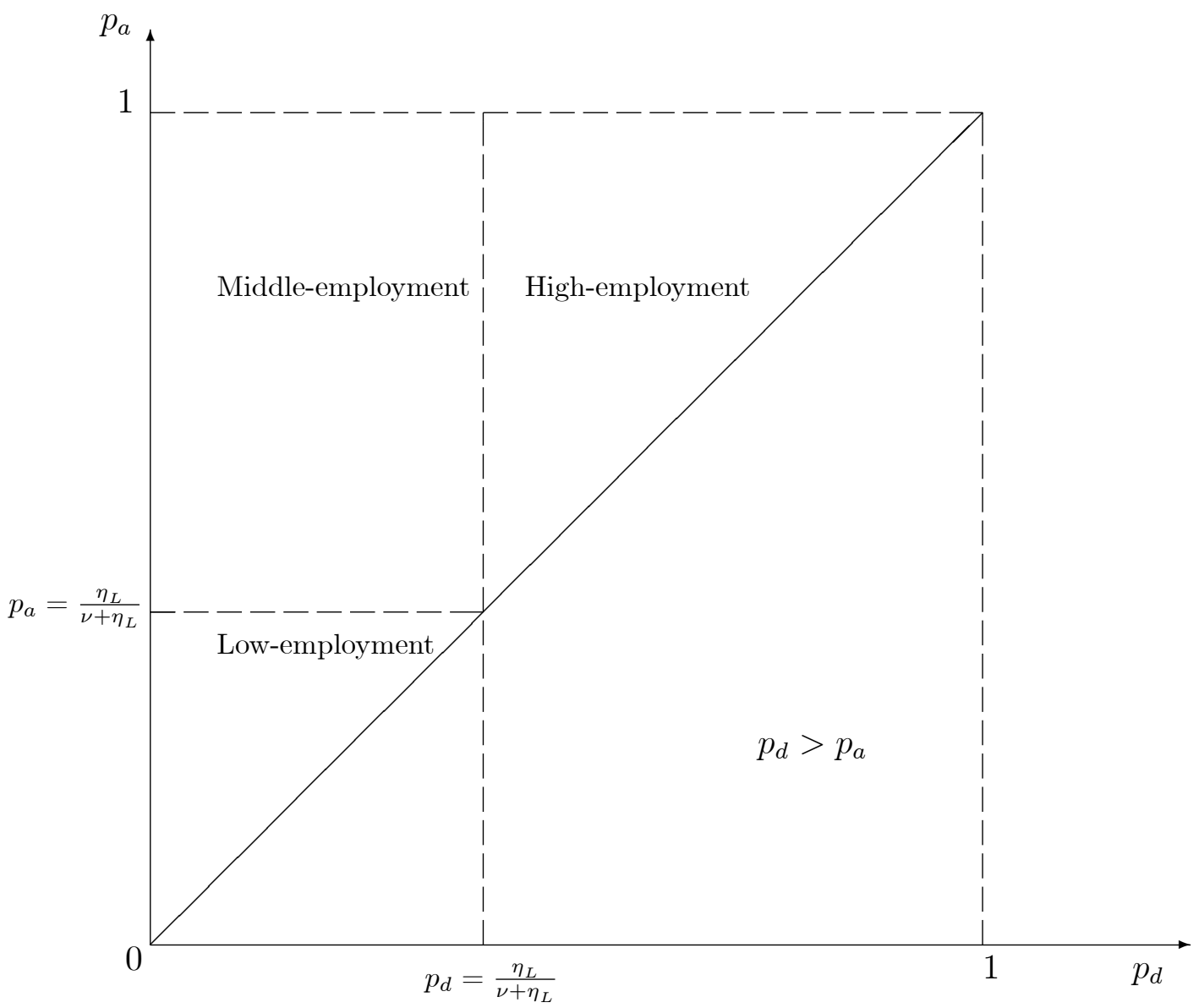

Figure 1 illustrates Proposition 1 when a given value of $\eta_{L}$ is considered. The assumption $p_{a}>p_{d}$ holds above the upward-sloping 45 degrees line.

To interpret Proposition 1, begin by looking at the key assumption, $p_{a}>p_{d}$. This makes the employer obtain a higher expected payoff by hiring advantaged students, given the same school strategy for every student. However this may not happen if the school gives extra teaching to a lower proportion of disadvantaged than advantaged and low-ability students, since this would increase the expected quality of the disadvantaged and high-grade students. 
When both $p_{d}$ and $p_{a}$ are higher than $\eta_{L} /\left(\nu+\eta_{L}\right)$ (high-employment equilibrium), the school maximises the amount of hired students by providing every student with extra teaching, since the employer thinks that a high grade student very likely has high ability, irrespective of her social background. In the other two cases, the school maximises the amount of hired disadvantaged students by giving less extra teaching to low-ability and disadvantaged compared to advantaged students.

In particular, when $p_{a}$ is higher and $p_{d}$ is lower than $\eta_{L} /\left(\nu+\eta_{L}\right)$ (middleemployment equilibrium), the employer still prefers advantaged rather than disadvantaged and high-grade students. When both $p_{d}$ and $p_{a}$ are lower than $\eta_{L} /\left(\nu+\eta_{L}\right)$ (low-employment equilibrium), the employer is indifferent between hiring an advantaged or a disadvantaged and high-grade student.

Proposition 1 shows that disadvantaged students are penalised compared to advantaged students in each possible case: they may receive less teaching, or be hired with lower probability to the employer, or both. In particular the high and middle-employment equilibrium, where disadvantaged students are penalised in the job market, exacerbate differences in social class.

Note that the probability $\eta_{L}$ can be interpreted as an inverse measure of educational standard. The educational standard measures the level of difficulty at school, how hard is to obtain a high grade ${ }^{11}$. Indeed as $\eta_{L}$ increases, obtaining a high grade becomes "easier" for some students. Thus the higher $\eta_{L}$, the lower the educational standard ${ }^{12}$.

Thus, these results suggest some interesting considerations about grade inflation. This is depicted where the educational standard is low $\left(\eta_{L}\right.$ high),

\footnotetext{
${ }^{11}$ The literature on educational standards examines the criteria adopted by schools in evaluating students. The theoretical frameworks on educational standards are provided by Costrell $(1994,1997)$ and Betts (1998). In the context of educational standards, the issue of social background has been introduced by Himmler and Schwager (2007), who show that a school with a large proportion of disadvantaged students applies less demanding standards since its students have less incentives to graduate.

${ }^{12}$ The educational standard can be employed as a tool for welfare analysis. A normative extension of our set-up can be considered for future work.
} 
since more low-ability students obtain a high grade. We can easily observe that when $\eta_{L}$ is high we are very likely to be in the low-employment equilibrium, where the employer is indifferent between hiring advantaged or disadvantaged and high-grade students. Indeed the presence of grade inflation diminishes the employer's expectations about students' ability. Since the school devotes less teaching effort to disadvantaged rather than advantaged and low-ability students, the grade inflation effect is stronger for advantaged students, leading to the low-employment equilibrium. Therefore grade inflation may have some positive effect by helping disadvantaged students to have the same job opportunities as advantaged students. This is in contrast with other results on grade inflation (Schwager, 2008), where the job opportunities of high-ability and disadvantaged students are penalised by the grade inflation of low-ability and advantaged students.

Finally, this result can be linked to the analysis of efficient provision of education. De Fraja (2005) shows that, in the presence of differences in social background, the optimal provision of education requires that disadvantaged and high-ability students receive more education than high-ability and advantaged students. According to Proposition 1, a school caring about the employment of its students does not devote more teaching effort to disadvantaged rather than advantaged and high-ability students. Therefore a policy intervention would be necessary to reach an efficient level of education.

\subsection{One social background}

In this section we assume no differences in social background. This allow us to highlight the role of other characteristics, such as the educational standard $\eta_{L}$ and the distribution of ability, and the school and employer technology.

We consider a population of disadvantaged students ${ }^{13}$, i.e., $\lambda=0$. Indeed, a population of only advantaged student $(\lambda=1)$ would make the high

\footnotetext{
${ }^{13}$ Note that, if $\lambda=0$ the middle or the low-employment equilibrium are equivalent for a disadvantaged student.
} 
and middle-employent equilibria be indeterminate. The following proposition shows which equilibrium takes place according to the value of $p_{d}$.

Proposition 2 Let Assumptions 1 and 2 hold and $\lambda=0$. The high-employment equilibrium occurs if $p_{d} \geq \eta_{L} /\left(\nu+\eta_{L}\right)$; the middle/low-employment equilibrium occurs if $p_{d}<\eta_{L} /\left(\nu+\eta_{L}\right)$.

Proof. See Appendix.

Figure 2. No differences in social background

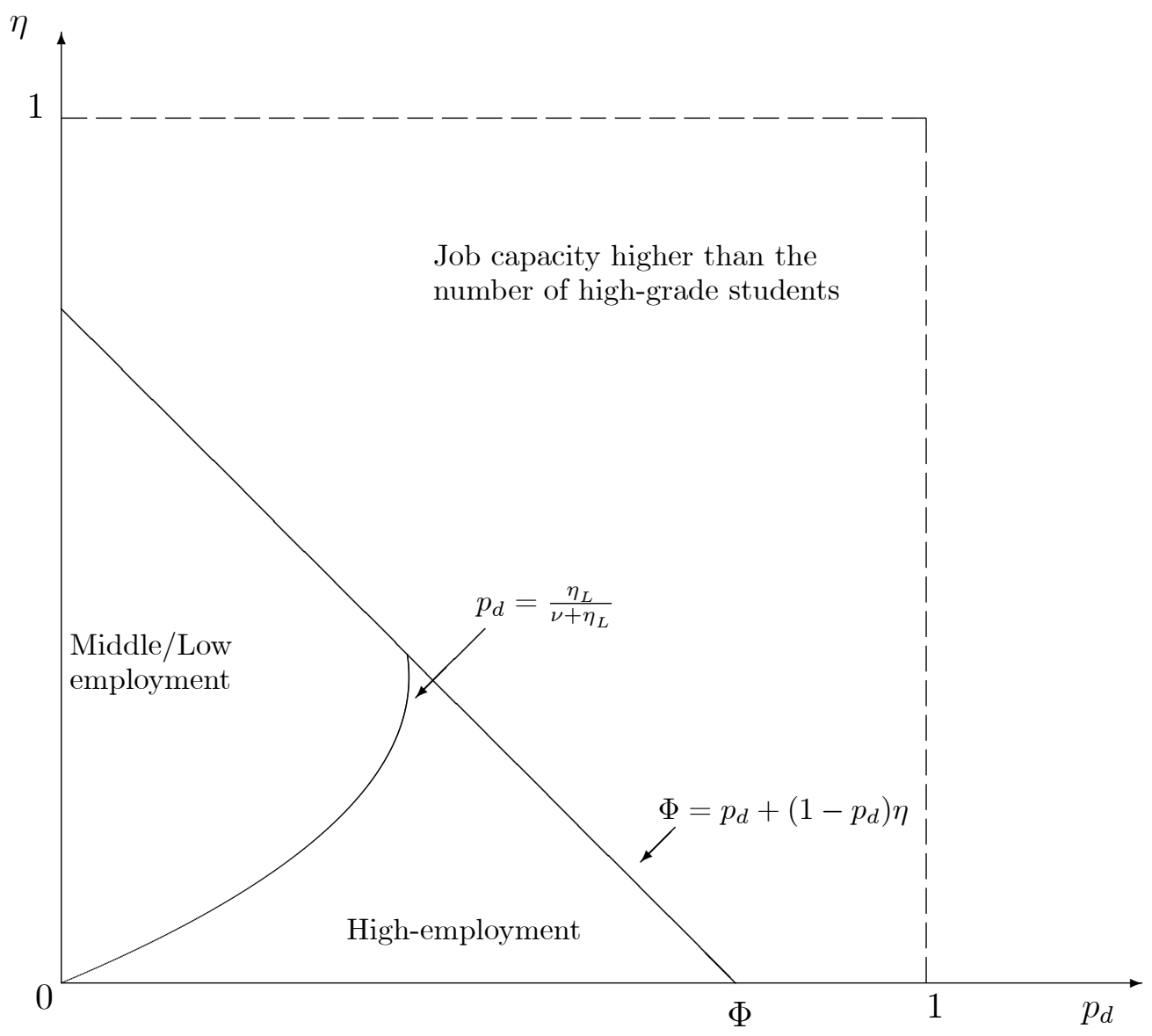

Figure 2 illustrates Proposition 2. Assumption 1 holds below the downwardsloping area. 
The equilibrium which occurs depends on $p_{d}$ and $\eta_{L}$. If the educational standard is high $\left(\eta_{L}\right.$ low) and $p_{d}$ is high, the equilibrium is high-employment. If $\eta_{L}$ is high and $p_{d}$ is low, the middle/low-employment equilibrium occurs. If both are high or low, which equilibrium occurs depends on which effect prevails.

The upward-sloping line represents the points where $p_{d}=\eta_{L} /\left(\nu+\eta_{L}\right)$. As the profit $\nu$ increases, the employer hires more students and the threshold shifts down. As the educational standard decreases $\left(\eta_{L}\right.$ high), the amount of low-ability and high-grade students increases. Therefore the employer hires less students and the threshold shifts up.

Finally, some considerations are necessary about the school strategy. Note that in the high-employment equilibrium, the school gives extra-teaching to all students even though some of them will not be hired. This happens because of Assumption 2, which ensures a very high school benefit from a student's employment. The cost of teaching a student who will not be hired is much smaller than the benefit loss incurred from a non-hired student who did not receive extra teaching.

\subsection{Analysis of equilibria}

In this section we study the properties of our equilibria. The following corollary shows some comparative statics results.

Corollary 1 A decrease in the educational standard (an increase in $\eta_{L}$ ) diminishes the employment opportunities and the provision of extra teaching; an increase in the employer's profit $\nu$ increases the provision of extra teaching; an increase in the proportion of advantaged students $\lambda$ increases the employment opportunities for disadvantaged students.

Proof. See Appendix.

An increase in $\eta_{L}$ makes the number of high-grade students increase. Thus their probability of being hired diminishes. In turn this makes the 
probability of receiving extra teaching diminish. An increase in $\nu$ leads to more employment opportunities, hence the school gives extra teaching to more low-ability students.

An increase in $\lambda$ has two contrasting effects in a high-employment equilibrium: the amount of disadvantaged and high-grade students diminishes and the employment opportunities for disadvantaged students are lowered. With the first effect, the probability of a disadvantaged and high-grade student being hired increases, while it diminishes with the second one. Nevertheless, the first effect more than offsets the second effect. The reason is the following: a decrease in the amount of disadvantaged and high-grade students increases job capacity relative to disadvantaged students $\left(\Phi /(1-\lambda)\left(p_{d}+\eta_{L}\left(1-p_{d}\right)\right)\right)$ with more intensity than it diminishes the relative employment placements $\left(-\lambda\left(p_{a}+\eta_{L}\left(1-p_{a}\right)\right) /(1-\lambda)\left(p_{d}+\eta_{L}\left(1-p_{d}\right)\right)\right)$. Therefore a higher proportion of advantaged students may increase the job opportunities of disadvantaged students.

\section{$4 \quad$ Subsidising disadvantaged students}

In many countries, governments spend substantial resources to fight unequal educational outcomes ${ }^{14}$. We can analyse such an intervention by considering a government that cannot observe the student's ability and subsidises the school of an amount $s \in(0,1]$ of its extra-teaching cost $c$ for all disadvantaged students. We examine the problem from a partial equilibrium perspective, in the sense that government taxation is not integrated into education subsidies.

\footnotetext{
${ }^{14}$ To cite some example, in 2001 the Department for Education in the USA funded "No Child Left Behind" (NCLB). This is a multi-billion dollar policy initiative to study the determinants of test score gaps among students of schooling age and prevent adverse effects in adulthood for those left behind at school. It helps to address such policy issues as low employment and wage profiles over time as well as health problems that lagging behind at school may lead to in adulthood. Since 2003 the Department for Education in the UK has funded "Every child matters" which is a similar policy initiative to NCLB but it puts additional emphasis on well-being and fostering positive behaviour in children.
} 
The following proposition shows the policy results.

Proposition 3 Assume that the government funds cs for every disadvantaged student receiving extra-teaching:

(i) if $p_{a} \geq p_{d} \geq \eta_{L} /\left(\nu+\eta_{L}\right)$, the high-employment equilibrium occurs (as before);

(ii) if $p_{a} \geq \eta_{L} /\left(\nu+\eta_{L}\right)>p_{d}$, the school strategy is

$$
x_{H a}=x_{H d}=x_{L a}=1, x_{L d}=\frac{p_{d}}{\left(1-p_{d}\right)} \frac{\nu}{\eta_{L}} \in(0,1),
$$

while the employer strategy is

$z_{U a}=1, z_{U d}=\min \left\{\frac{c(1-s)}{\mu \eta_{L}}, \frac{\Phi-\lambda\left(p_{a}+\eta_{L}\left(1-p_{a}\right)\right)}{(1-\lambda)\left(p_{d}(1+\nu)\right)}\right\} \in(0,1), z_{D a}=z_{D d}=0$.

(iii) if $p_{d}<p_{a}<\eta_{L} /\left(\nu+\eta_{L}\right)$, the school strategy is

$$
x_{H a}=x_{H d}=1, x_{L a}=\frac{p_{a}}{\left(1-p_{a}\right)} \frac{\nu}{\eta_{L}} \in(0,1), x_{L d}=\frac{p_{d}}{\left(1-p_{d}\right)} \frac{\nu}{\eta_{L}} \in(0,1),
$$

while the employer strategy is

$$
\begin{gathered}
z_{U a}=\min \left\{\frac{c}{\mu \eta_{L}}, \frac{\Phi}{\left(\lambda p_{a}+(1-s)(1-\lambda) p_{d}\right)(1+\nu)}\right\}, \\
, z_{U d}=\min \left\{\frac{c(1-s)}{\mu \eta_{L}}, \frac{\Phi-\frac{c}{\mu \eta_{L}} \lambda p_{a}(1+\nu)}{\left.(1-\lambda) p_{d}\right)(1+\nu)}\right\}, z_{D a}=z_{D d}=0 .
\end{gathered}
$$

Proof. See Appendix.

In case (i) $\left(p_{a} \geq \eta_{L} /\left(\nu+\eta_{L}\right)\right.$ and $\left.p_{d} \geq \eta_{L} /\left(\nu+\eta_{L}\right)\right)$, the policy does not have any effect whatsoever, since the school would have given extra teaching to every student even if no policy was applied.

In cases (ii) and (iii), as $s$ increases, the probability that a disadvantaged student is hired decreases. In the case (iii) also, the disadvantaged and highgrade student does not have hiring opportunities as good as an advantaged 
student, like in the case $p_{d}<p_{a}<\eta_{L} /\left(\nu+\eta_{L}\right)$ without subsidy. Finally, when $s=1$ (full subsidising), the school gives extra teaching to all disadvantaged students and the employer never hires a disadvantaged student.

Thus the policy might worsen her hiring opportunities. The reason is intuitive. The lower the school extra-teaching cost for a disadvantaged student, the lower the credibility of a high grade as a signal of high ability if $p_{d}$ is low. Providing only high-ability students with extra teaching is not a credible strategy, as ex post the school would give it even to low-ability students.

No policy conclusion should be drawn from it. However this analysis suggests care should be taken in policy choices, since the attempt to improve the schooling attainment of disadvantaged students might in fact diminish their job opportunities.

\section{Concluding remarks}

This paper examines how social background affects school's teaching and an employer's recruitment. We analysed the interaction between a school and an employer when students attend school and then apply for a job. Our results suggest that disadvantaged students are penalised compared to advantaged students, as they receive less teaching and/or are less likely to be hired.

The policy considerations can be extended in many directions. The government might impose some restriction on the employer strategy in order to favour disadvantaged students, like in the case of affirmative action. For instance, the employer might be forced to hire a certain number of disadvantaged students. In welfare analysis a policy can be considered where the educational standard $\left(\eta_{L}\right)$ is set to maximize welfare.

Furthermore, the framework can be developed in several ways, two of which we discuss briefly. First, it seems natural to consider different schools for each social group by taking into account differences in quality of teaching. 
Second, it would be interesting to examine this framework alongside different generations for explaining segregation or inequality. The analysis of an extended model regarding these expansions is left for future work.

\section{References}

[1] Arnott, R. and Rowse, J. 1987. Peer group effects and educational attainment. Journal of Public Economics 32: 287-305.

[2] Betts, J. 1998. The impact of educational standards on the level and distribution of earnings, American Economic Review 88: 266-275.

[3] Carneiro, P. and Heckman, J.J. 2003. Human capital policy. In Heckman, J. J., and Krueger, A.B. 2003. Inequality in America: What role for human capital policies? The MIT Press.

[4] Chan, W., L., Hao, and Suen, W. 2007. A signalling theory of grade inflation, International Economic Review 48: 1065-1090.

[5] Costrell, R. 1994. A simple model of educational standards, American Economic Review 84: 956-971.

[6] Costrell, R. 1997. Can centralized educational standards raise welfare? Journal of Public Economics 65: 271-293.

[7] Cunha, F., Heckman, J.J., Lochner, L., and Masterov, D. V. 2005. Interpreting the evidence on life cycle skill formation. NBER 11331.

[8] De Bartolome, C. 1990. Equilibrium and inefficiency in a community model with peer group effects. Journal of Political Economy 98: 110-133.

[9] De Fraja, G. 2005. Reverse discrimination and efficiency in education. International Economic Review. 46: 1009-1031. 
[10] Epple, D. and Romano, R. E. 1998. Competition between private and public schools, vouchers and peer group effects. American Economic Review 88: 33-62.

[11] Epple, D., Romano, R. E. and Sieg, H. 2003. Peer effects financial aid and selection of students to colleges and universities: an empirical analysis. Journal of Applied Econometrics 18: 501-525.

[12] Galindo-Rueda, F., and Vignoles, A. 2005. The declining relative importance of ability in predicting educational attainment. Journal of Human Resources 2: 335353.

[13] Gibbons, R. 1992. A primer in game theory. Harvester-Wheatsheaf. Hemel Hempstead.

[14] Haveman, R., and Wolfe, B. 1995. The determinants of children's attainments: A review of methods and findings. Journal of Economic Literature 33: 1829-78.

[15] Henderson, V., Mieszkowski, P. and Sauvageau, Y. 1978. Peer group effects in educational production function. Journal of Public Economics 10: 97-106.

[16] Himmler, O. and R. Schwager 2007. Double standards in educational standards: Are disadvantaged students being graded more leniently? ZEW Discussion Paper 07-016.

[17] Joshi, H. E., and McCulloch, A. 2001. Neighbourhood and family influences on the cognitive ability of children in the British national child development study. Social Science and Medicine 53: 579-591.

[18] Moreland, R.L. and Levine, J.M. 1992. The composition of small groups. In: Lawler, E.J., Markovsky, B., Ridgeway, C., Walker, H. (Eds.), Advances in Group Processes, vol. 9. JAI Press, Greenwich, CT: 237-280.

[19] Riley, J.G. 2001. Silver signals: twenty-five years of screening and signalling. Journal of Economic Literature 39: 432-478.

[20] Rourke, E. and Ingram, F. 1991. Educational Testing Service. International Directory of Company Histories. 
[21] Schwager 2008. Grade inflation, social background and labour market matching. ZEW Discussion Paper 08-070.

[22] Spence, M. 1973. Job market signalling. The Quarterly Journal of Economics 87: $355-374$.

[23] Stanford Encyclopedia of Philosophy:http://plato.stanford.edu/entries/affirmativeaction/.

[24] Summers, A.A. and Wolfe, B.L. 1977. Do schools make a difference? American Economic Review 67: 639-652.

[25] Waldmann, M. 1984. Job assignment, signalling and efficiency. The RAND Journal of Economics 15: 255-267.

[26] Zimmer, R. W. and Toma, E. F. 2000. Peer effects in private and public schools across countries. Journal of Policy Analysis and Management 19: 75-92.

\section{Appendix}

\section{List of symbols}

- $\theta_{H}$ : high ability.

- $\theta_{L}$ : low ability.

- $a$ : advantaged social background.

- $d$ : disadvantaged social background.

- $p_{a} \in[0,1]$ : probability that an advantaged student has high-ability.

- $p_{d} \in[0,1]$ : probability that a disadvantaged student has high-ability.

- $\lambda \in[0,1)$ : proportion of advantaged students. 
- $\eta_{H} \in[0,1]:$ probability that a high-ability student not receiving extra teaching will obtain a high grade.

- $\eta_{L} \in[0,1]:$ probability that a low-ability student receiving extra teaching will obtain a high grade.

- $\Phi \in[0,1]$ : job capacity.

- $g_{U}$ : high grade.

- $g_{D}$ : low grade.

- $\nu$ : employer's payoff for hiring a high-ability student.

- $\mu$ : school's benefit when a student is hired.

- $c$ : school's cost when a student receives extra teaching.

- $H\left(\theta_{H}\right)$ : number of hired students with high ability.

- $H\left(\theta_{L}\right)$ : number of hired students with low ability.

- ET: number of students receiving extra teaching.

- $x_{L a}, x_{H a}, x_{L d}, x_{H d} \in[0,1]:$ probabilities that the school gives extra teaching to an advantaged and low or high-ability student and to a disadvantaged and low or high-ability student, respectively.

- $z_{U a}, z_{D a}, z_{U d}, z_{D d} \in[0,1]:$ probabilities that the employer hires an advantaged student with a high or low grade and a disadvantaged student with a high or low grade, respectively.

- $\pi\left(\theta_{z} \mid g_{j}, p_{i}, x_{z i}\right)$ : employer's belief about a student's ability.

- $i \in\{a, d\}$ : social background.

- $z \in\{H, L\}$ : ability level. 
- $j \in\{U, D\}$ : possible grade.

- $s \in[0,1]$ : government subsidy of school extra-teaching costs for a disadvantaged student.

- $\Pi_{j i}^{E}$ : employer's expected payoff of hiring a student.

- $\Pi_{j i}^{N}$ : employer's expected payoff of not hiring a student.

- $\Pi_{z i}^{T}$ : school expected payoff of giving extra teaching to a student.

- $\Pi_{z i}^{N T}$ : school expected payoff of not giving extra teaching to a student.

\section{Proof of Proposition 1 and 2}

The proof follows Proposition 1. By setting $\lambda=0$ we obtain the proof of Proposition 2.

Case 1. $p_{a} \geq p_{d} \geq \eta_{L} /\left(\nu+\eta_{L}\right)$

Employer. The employer strategy is

$$
z_{U a}=1 ; z_{D a}=0, z_{U d}=\frac{\Phi-\lambda\left(p_{a}+\eta_{L}\left(1-p_{a}\right)\right)}{(1-\lambda)\left(p_{d}+\eta_{L}\left(1-p_{d}\right)\right)} ; z_{D d}=0 .
$$

The employer's beliefs for advantaged students are

$$
\pi\left(\theta_{H} \mid g_{U}, a\right)=\frac{p_{a}}{p_{a}+\eta_{L}\left(1-p_{a}\right)}
$$

and

$$
\pi\left(\theta_{L} \mid g_{U}, a\right)=\frac{\eta_{L}\left(1-p_{a}\right)}{p_{a}+\eta_{L}\left(1-p_{a}\right)},
$$

if the student has a high grade and $\pi\left(\theta_{H} \mid g_{D}, a\right)=0$ and $\pi\left(\theta_{L} \mid g_{D}, a\right)=1$ if the student has a low grade. Thus the expected profit ${ }^{15}$ for hiring an

\footnotetext{
${ }^{15}$ The superscript of the employer's expected profit indicates the action performed by the employer, where $E$ indicates "to hire" and $N$ "to not". The subscript specifies the
} 
advantaged and high-grade student is

$$
\Pi_{U a}^{E}=\frac{p_{a}}{p_{a}+\eta_{L}\left(1-p_{a}\right)} \nu-\frac{\eta_{L}\left(1-p_{a}\right)}{p_{a}+\eta_{L}\left(1-p_{a}\right)}
$$

This must be

$$
\frac{p_{a}}{p_{a}+\eta_{L}\left(1-p_{a}\right)} \nu-\frac{\eta\left(1-p_{a}\right)}{p_{a}+\eta_{L}\left(1-p_{a}\right)} \geq 0
$$

and, after few passages, $p_{a} \geq \eta_{L} /\left(\nu+\eta_{L}\right)$. The expected profits for hiring and not hiring an advantaged and low-grade student are $\Pi_{D a}^{E}=-1$ and $\Pi_{D a}^{N}=0$, respectively, thus $\Pi_{D a}^{E}<\Pi_{D a}^{N}$.

The employer's beliefs for disadvantaged students are

$$
\pi\left(\theta_{H} \mid g_{U}, d\right)=\frac{p_{d}}{p_{d}+\eta_{L}\left(1-p_{d}\right)}
$$

and

$$
\pi\left(\theta_{L} \mid g_{U}, d\right)=\frac{\eta_{L}\left(1-p_{d}\right)}{p_{d}+\eta_{L}\left(1-p_{d}\right)},
$$

if the student has a high grade and $\pi\left(\theta_{H} \mid g_{D}, d\right)=0$ and $\pi\left(\theta_{L} \mid g_{D}, d\right)=1$ if the student has a low grade. The expected profit for hiring one disadvantaged and high-grade student is

$$
\Pi_{U d}^{E}=\frac{p_{d}}{p_{d}+\eta_{L}\left(1-p_{d}\right)} \nu-\frac{\eta_{L}\left(1-p_{d}\right)}{p_{d}+\eta_{L}\left(1-p_{d}\right)}
$$

This must be

$$
\frac{p_{a}}{p_{a}+\eta_{L}\left(1-p_{a}\right)} \nu-\frac{\eta_{L}\left(1-p_{a}\right)}{p_{a}+\eta_{L}\left(1-p_{a}\right)} \geq 0
$$

and, after few passages, $p_{d} \geq \eta_{L} /\left(\nu+\eta_{L}\right)$. The expected profits for hiring and not hiring a disadvantaged and low-grade student are $\Pi_{D d}^{E}=-1$ and student's grade, where $U$ and $D$ stands for high and low grade, respectively, while $a$ and $d$ indicates the student's social background. 
$\Pi_{D d}^{N}=0$, respectively, thus $\Pi_{D d}^{E}<\Pi_{D d}^{N}$.

Then the employer needs to compare the expected profit obtained by high grade students with different social background ${ }^{16}$ : this is $\Pi_{U a}^{E}>\Pi_{U d}^{E}$, as $p_{a}>p_{d}$. As a consequence,the employer admits all the advantaged and high-grade students and the disadvantaged ones only for the remainder of job capacity. Given the restrictions on job capacity, the number of hired disadvantaged and high grade students is

$$
\frac{\Phi-\lambda\left(p_{a}+\eta_{L}\left(1-p_{a}\right)\right)}{(1-\lambda)\left(p_{d}+\eta_{L}\left(1-p_{d}\right)\right)}
$$

School. The school strategy is $x_{L a}=1 ; x_{H a}=1, x_{L d}=1 ; x_{H d}=1$. The expected payoffs ${ }^{17}$ for giving or not giving extra teaching to an advantaged and high-ability student are $\Pi_{H a}^{T}=\mu-c$ and $\Pi_{H a}^{N T}=\mu \eta_{H}$, respectively. This must be $\Pi_{H a}^{T}>\Pi_{H a}^{N T}$, that is $\mu-c \geq \mu \eta_{H}$, and therefore $\mu \geq c /\left(1-\eta_{H}\right)$. The expected payoffs for giving or not giving extra teaching to an advantaged and low-ability student are $\Pi_{L a}^{T}=\mu \eta_{L}-c$ and $\Pi_{H a}^{N T}=0$, respectively. This must be $\Pi_{L a}^{T} \geq \Pi_{L a}^{N T}$, that is $\mu \eta_{L}-c \geq 0$, and therefore $\mu \geq \frac{c}{\eta_{L}}$.

The expected payoffs for giving or not giving extra teaching to a disadvantaged and high-ability student are $\Pi_{H d}^{T}=\mu z_{U d}-c$ and $\Pi_{H d}^{N T}=\mu \eta_{H} z_{U d}$, respectively. This must be $\Pi_{H d}^{T} \geq \Pi_{H d}^{N T}$, that is $\mu z_{U d}-c \geq \mu z_{U d} \eta_{H}$, and therefore $\mu \geq c /\left(z_{U d}\left(1-\eta_{H}\right)\right)$. The expected payoffs for giving or not giving extra teaching to a disadvantaged and low-ability student are $\Pi_{L d}^{T}=\mu \eta_{L} z_{U d}-c$ and $\Pi_{H d}^{N T}=0$, respectively. This must be $\Pi_{L d}^{T} \geq \Pi_{L d}^{N T}$, that is $\mu \eta_{L} z_{U d}-c \geq 0$, and therefore $\mu \geq c / z_{U d} \eta$.

\footnotetext{
${ }^{16}$ This is not necessary for low-grade students as none of them are admitted.

${ }^{17}$ The superscript of the school's expected payoff indicates the action performed by the school, where $T$ and $N T$ stands for "to give" and "not to give extra-teaching". The subscript specifies the student's ability, where $H$ stands for high ability and $L$ low ability, while $a$ and $d$ indicates the student's social background.
} 
Job capacity. The total number of hired students is:

$$
\lambda\left(p_{a}+\eta_{L}\left(1-p_{a}\right)\right)+(1-\lambda)\left(p_{d}+\eta_{L}\left(1-p_{d}\right)\right) \frac{\Phi-\lambda\left(p_{a}+\eta_{L}\left(1-p_{a}\right)\right)}{(1-\lambda)\left(p_{d}+\eta_{L}\left(1-p_{d}\right)\right)} \equiv \Phi .
$$

Case 2. $p_{a} \geq \eta_{L} /\left(\nu+\eta_{L}\right)>p_{d}$

As $p_{a} \geq \eta_{L} /\left(\nu+\eta_{L}\right)$, the employer and school strategy for advantaged students does not change compared to the previous case.

Employer. The employer strategy is

$$
z_{U a}=1 ; z_{D a}=0, z_{U d}=\min \left\{\frac{c}{\mu \eta_{L}}, \frac{\Phi-\lambda\left(p_{a}+\eta_{L}\left(1-p_{a}\right)\right)}{(1-\lambda)\left(p_{d}(1+\nu)\right)}\right\} ; z_{D d}=0 .
$$

The employer's beliefs for disadvantaged students are

$$
\pi\left(\theta_{H} \mid g_{U}, d\right)=\frac{p_{d}}{p_{d}+\eta_{L} x_{L d}\left(1-p_{d}\right)}
$$

and

$$
\pi\left(\theta_{L} \mid g_{U}, d\right)=\frac{\eta_{L} x_{L d}\left(1-p_{d}\right)}{p_{d}+\eta_{L} x_{L d}\left(1-p_{d}\right)},
$$

if the student has a high grade and $\pi\left(\theta_{H} \mid g_{D}, d\right)=0$ and $\pi\left(\theta_{L} \mid g_{D}, d\right)=$ 1 if the student has a low grade. Thus the expected profit for hiring an advantaged and high-grade student is

$$
\Pi_{U d}^{E}=\frac{p_{d}}{p_{d}+\eta_{L} x_{L d}\left(1-p_{d}\right)} \nu-\frac{\eta_{L} x_{L d}\left(1-p_{d}\right)}{p_{d}+\eta_{L} x_{L d}\left(1-p_{d}\right)} .
$$

This must be

$$
\frac{p_{d}}{p_{d}+\eta_{L} x_{L d}\left(1-p_{d}\right)} \nu-\frac{\eta_{L} x_{L d}\left(1-p_{d}\right)}{p_{d}+\eta_{L} x_{L d}\left(1-p_{d}\right)}=0
$$

and, after few passages, $x_{L d}=p_{d} \nu /\left(1-p_{d}\right) \eta_{L}$. To be a probability, then $p_{d} \nu /\left(1-p_{d}\right) \eta_{L}<1$, by which $p_{d}<\eta_{L} /\left(\nu+\eta_{L}\right)$. The expected profits for hiring and not hiring a disadvantaged and low-grade student are $\Pi_{D d}^{E}=-1$ 
and $\Pi_{D d}^{N}=0$, respectively, thus $\Pi_{D d}^{E}<\Pi_{D d}^{N}$.

Then the employer needs to compare the expected profit obtained by high grade students with different social background: this is $\Pi_{U a}^{E}>\Pi_{U d}^{E}$, as $\Pi_{U a}^{E}>0$, while $\Pi_{U d}^{E}=0$.

School. The school strategy is $x_{L a}=1 ; x_{H a}=1 ; x_{L d}=p_{d} \nu /\left(1-p_{d}\right) \eta_{L}$; $x_{H d}=1$. The expected payoffs for giving or not giving extra teaching to a disadvantaged and high-ability student are $\Pi_{H d}^{T}=\mu z_{U d}-c$ and $\Pi_{H d}^{N T}=$ $\mu \eta_{H} z_{U d}$, respectively. This must be $\Pi_{H d}^{T} \geq \Pi_{H d}^{N T}$, that is $\mu z_{U d}-c \geq \mu \eta_{H} z_{U d}$, and therefore $\mu \geq c / z_{U d}\left(1-\eta_{H}\right)$. The expected payoffs for giving or not giving extra teaching to a disadvantaged and low-ability student are $\Pi_{L d}^{T}=$ $z_{U d} \mu \eta_{L}-c$ and $\Pi_{H d}^{N T}=0$, respectively. This must be $\Pi_{L d}^{T}=\Pi_{L d}^{N T}$, that is $z_{U d} \mu \eta_{L}-c=0$, and therefore $z_{U d}=c / \mu \eta_{L}$.

Job capacity. The total number of hired students ${ }^{18}$ is:

$$
\lambda\left(p_{a}+\eta_{L}\left(1-p_{a}\right)\right)+(1-\lambda)\left(p_{d}(1+\nu)\right) \frac{c}{\mu \eta_{L}} \leq \Phi,
$$

thus job capacity implies

$$
z_{U d}=\min \left\{\frac{c}{\mu \eta_{L}}, \frac{\Phi-\lambda\left(p_{a}+\eta_{L}\left(1-p_{a}\right)\right)}{(1-\lambda)\left(p_{d}(1+\nu)\right)}\right\} .
$$

Case 3. $p_{d}<p_{a}<\eta_{L} /\left(\nu+\eta_{L}\right)$

As $p_{d}<\eta_{L} /\left(\nu+\eta_{L}\right)$, the employer and school strategy for disadvantaged students does not change compared to the previous case.

Employer. The employer strategy is

$$
z_{U a}, z_{U d}=\min \left\{\frac{c}{\mu \eta_{L}}, \frac{\Phi}{\left(\lambda p_{a}+(1-\lambda) p_{d}\right)(1+\nu)}\right\} ; z_{D a}=0 ; z_{D d}=0 .
$$

\footnotetext{
${ }^{18}$ Note that the number of disadvantaged and high-grade students in this equilibrium is $(1-\lambda)\left(p_{d}+\eta\left(1-p_{d}\right) x_{L d}\right)$ where $x_{L d}=p_{d} \nu /\left(1-p_{d}\right) \eta_{L}$. By substituting we obtain $(1-\lambda)\left(p_{d}+\eta\left(1-p_{d}\right) p_{d} \nu /\left(1-p_{d}\right) \eta_{L}\right)$, which can be simplified in $(1-\lambda)\left(p_{d}(1+\nu)\right)$.
} 
The employer's beliefs for advantaged students are

$$
\pi\left(\theta_{H} \mid g_{U}, a\right)=\frac{p_{a}}{p_{a}+\eta_{L} x_{L a}\left(1-p_{a}\right)}
$$

and

$$
\pi\left(\theta_{L} \mid g_{U}, a\right)=\frac{\eta_{L} x_{L a}\left(1-p_{a}\right)}{p_{a}+\eta_{L} x_{L a}\left(1-p_{a}\right)}
$$

if the student has a high grade and $\pi\left(\theta_{H} \mid g_{D}, a\right)=0$ and $\pi\left(\theta_{L} \mid g_{D}, a\right)=$ 1 if the student has a low grade. Thus the expected profit for hiring an advantaged and high-grade student is

$$
\Pi_{U a}^{E}=\frac{p_{a}}{p_{a}+\eta_{L} x_{L a}\left(1-p_{a}\right)} \nu-\frac{\eta_{L} x_{L a}\left(1-p_{a}\right)}{p_{a}+\eta_{L} x_{L a}\left(1-p_{a}\right)} .
$$

This must be

$$
\frac{p_{a}}{p_{a}+\eta_{L} x_{L a}\left(1-p_{a}\right)} \nu-\frac{\eta_{L} x_{L a}\left(1-p_{a}\right)}{p_{a}+\eta_{L} x_{L a}\left(1-p_{a}\right)}=0
$$

and, after few passages, $x_{L a}=p_{a} \nu /\left(1-p_{a}\right) \eta_{L}$. To be a probability, it is necessary that $p_{a} \nu /\left(1-p_{a}\right) \eta_{L}<1$, by which $p_{a}<\eta_{L} /\left(\nu+\eta_{L}\right)$. The expected profits for hiring and not hiring an advantaged and low-grade student are $\Pi_{D a}^{E}=-1$ and $\Pi_{D a}^{N}=0$, respectively, thus $\Pi_{D a}^{E}<\Pi_{D a}^{N}$.

Then the employer needs to compare the expected profit obtained by high grade students with different social background: this is $\Pi_{U a}^{E}=\Pi_{U d}^{E}$, as both $\Pi_{U a}^{E}=0$ and $\Pi_{U d}^{E}=0$.

School. The school strategy is $x_{L a}=p_{a} \nu /\left(1-p_{a}\right) \eta_{L} ; x_{H a}=1 ; x_{L d}=$ $p_{d} \nu /\left(1-p_{d}\right) \eta_{L} ; x_{H d}=1$. The expected payoffs for giving or not giving extra teaching to an advantaged and high-ability student are $\Pi_{H a}^{T}=\mu z_{U a}-c$ and $\Pi_{H a}^{N T}=\mu \eta_{H} z_{U a}$, respectively. This must be $\Pi_{H a}^{T} \geq \Pi_{H a}^{N T}$, that is $\mu z_{U a}-c \geq$ $\mu \eta_{H} z_{U a}$, and therefore $\mu \geq c /\left(z_{U a}(1-\eta)\right)$. The expected payoffs for giving or not giving extra teaching to a disadvantaged and low-ability student are $\Pi_{L a}^{T}=\mu z_{U a} \eta_{L}-c$ and $\Pi_{H d}^{N T}=0$, respectively. This must be $\Pi_{L a}^{T}=\Pi_{L a}^{N T}$, 
that is $\mu z_{U a} \eta_{L}-c=0$, and therefore $z_{U a}=c / \mu \eta_{L}$.

Job capacity. The total number of hired students ${ }^{19}$ is:

$$
\frac{c}{\mu \eta_{L}}(1+\nu)\left(\lambda p_{a}+(1-\lambda) p_{d}\right) \leq \Phi,
$$

thus job capacity implies

$$
z_{U d}=\min \left\{\frac{c}{\mu \eta_{L}}, \frac{\Phi}{\left(\lambda p_{a}+(1-\lambda) p_{d}\right)(1+\nu)}\right\} .
$$

\section{Proof of corollary 1}

High-employment equilibrium. Differentiation of

$$
\frac{\Phi-\lambda\left(p_{a}+\eta_{L}\left(1-p_{a}\right)\right)}{(1-\lambda)\left(p_{d}+\eta_{L}\left(1-p_{d}\right)\right)}
$$

with respect to $\eta_{L}$, and $\lambda$ yields

$$
\begin{gathered}
\frac{\partial}{\partial \eta_{L}} \frac{\Phi-\lambda\left(p_{a}+\eta_{L}\left(1-p_{a}\right)\right)}{(1-\lambda)\left(p_{d}+\eta_{L}\left(1-p_{d}\right)\right)}= \\
\frac{\lambda}{\lambda-1} \frac{1-p_{a}}{p_{d}+\eta_{L}\left(1-p_{d}\right)}+\frac{\left(1-p_{d}\right)\left(\Phi-\lambda\left(p_{a}+\eta_{L}\left(1-p_{a}\right)\right)\right)}{(\lambda-1)\left(p_{d}-\eta_{L}\left(p_{d}-1\right)\right)^{2}}<0,
\end{gathered}
$$

and

$$
\frac{\partial}{\partial \lambda} \frac{\Phi-\lambda\left(p_{a}+\eta_{L}\left(1-p_{a}\right)\right)}{(1-\lambda)\left(p_{d}+\eta_{L}\left(1-p_{d}\right)\right)}=\frac{\Phi-\left(p_{a}+\eta_{L}\left(1-p_{a}\right)\right)}{(\lambda-1)^{2}\left(p_{d}+\eta_{L}\left(1-p_{d}\right)\right)}>0
$$

respectively.

Middle-employment equilibrium. Differentiation of $c / \mu \eta_{L}$ with re-

\footnotetext{
${ }^{19}$ Note that the number of advantaged and high-grade students in this equilibrium is $\lambda\left(p_{a}+\eta\left(1-p_{a}\right) x_{L a}\right)$ where $x_{L a}=\frac{p_{a}}{\left(1-p_{a}\right)} \frac{\nu}{\eta}$. By substituting we obtain $\lambda\left(p_{a}+\eta\left(1-p_{a}\right) \frac{p_{a}}{\left(1-p_{a}\right)} \frac{\nu}{\eta}\right)$, which can be simplified in $\lambda\left(p_{a}(1+\nu)\right)$.
} 
spect to $\eta_{L}$ yields

$$
\frac{\partial}{\partial \eta_{L}} \frac{c}{\mu \eta_{L}}=-\frac{c}{\mu \eta_{L}^{2}}<0 .
$$

Differentiation of $p_{d} \nu /\left(1-p_{d}\right) \eta_{L}$ with respect to $\eta_{L}$ and $\nu$ yields

$$
\frac{\partial}{\partial \eta_{L}} \frac{p_{d}}{\left(1-p_{d}\right)} \frac{\nu}{\eta_{L}}=\frac{\nu p_{d}}{\eta_{L}^{2}\left(p_{d}-1\right)}<0,
$$

and

$$
\frac{\partial}{\partial \nu} \frac{p_{d}}{\left(1-p_{d}\right)} \frac{\nu}{\eta_{L}}=\frac{1}{\eta_{L}} \frac{p_{d}}{1-p_{d}}>0
$$

respectively.

Low-employment equilibrium. Differentiation of $p_{d} \nu /\left(1-p_{d}\right) \eta_{L}$ with respect to $\eta_{L}$ and $\nu$ yields

$$
\frac{\partial}{\partial \eta_{L}} \frac{p_{a}}{\left(1-p_{a}\right)} \frac{\nu}{\eta_{L}}=\frac{\nu}{\eta_{L}^{2}} \frac{p_{a}}{p_{a}-1}<0,
$$

and

$$
\frac{\partial}{\partial \nu} \frac{p_{a}}{\left(1-p_{a}\right)} \frac{\nu}{\eta_{L}}=\frac{1}{\eta_{L}} \frac{p_{a}}{1-p_{a}}>0
$$

respectively.

\section{Proof of Proposition 3}

For each disadvantaged student, the government subsidises $c s$. This does not changes anything in Case 1 , as the school strategy was $x_{L d}=1 ; x_{H d}=1$.

Case 2. $p_{a} \geq \eta_{L} /\left(\nu+\eta_{L}\right)>p_{d}$

For advantaged students we refer to Proof: Case 2 of Proposition 2.

Employer. The employer strategy is

$$
z_{U a}=1 ; z_{D a}=0, z_{U d}=\min \left\{\frac{c(1-s)}{\mu \eta_{L}}, \frac{\Phi-\lambda\left(p_{a}+\eta_{L}\left(1-p_{a}\right)\right)}{(1-\lambda)\left(p_{d}(1+\nu)\right)}\right\} ; z_{D d}=0 .
$$


The employer's beliefs for disadvantaged students are

$$
\pi\left(\theta_{H} \mid g_{U}, d\right)=\frac{p_{d}}{p_{d}+\eta_{L} x_{L d}\left(1-p_{d}\right)}
$$

and

$$
\pi\left(\theta_{L} \mid g_{U}, d\right)=\frac{\eta_{L} x_{L d}\left(1-p_{d}\right)}{p_{d}+\eta_{L} x_{L d}\left(1-p_{d}\right)}
$$

if the student has a high grade and $\pi\left(\theta_{H} \mid g_{D}, d\right)=0$ and $\pi\left(\theta_{L} \mid g_{D}, d\right)=$ 1 if the student has a low grade. Thus the expected profit for hiring an advantaged and high-grade student is

$$
\Pi_{U d}^{E}=\frac{p_{d}}{p_{d}+\eta_{L} x_{L d}\left(1-p_{d}\right)} \nu-\frac{\eta_{L} x_{L d}\left(1-p_{d}\right)}{p_{d}+\eta_{L} x_{L d}\left(1-p_{d}\right)}
$$

This must be

$$
\frac{p_{d}}{p_{d}+\eta_{L} x_{L d}\left(1-p_{d}\right)} \nu-\frac{\eta_{L} x_{L d}\left(1-p_{d}\right)}{p_{d}+\eta_{L} x_{L d}\left(1-p_{d}\right)}=0
$$

and, after few passages, $x_{L d}=p_{d} \nu /\left(1-p_{d}\right) \eta_{L}$. To be a probability, then $p_{d} \nu /\left(1-p_{d}\right) \eta_{L}<1$, by which $p_{d}<\eta_{L} /\left(\nu+\eta_{L}\right)$. The expected profits for hiring and not hiring a disadvantaged and low-grade student are $\Pi_{D d}^{E}=-1$ and $\Pi_{D d}^{N}=0$, respectively, thus $\Pi_{D d}^{E}<\Pi_{D d}^{N}$.

Then the employer needs to compare the expected profit obtained by high grade students with different social background: this is $\Pi_{U a}^{E}>\Pi_{U d}^{E}$, as $\Pi_{U a}^{E}>0$, while $\Pi_{U d}^{E}=0$.

School. The school strategy is $x_{L a}=x_{H a}=1 ; x_{L d}=p_{d} \nu /\left(1-p_{d}\right) \eta_{L}$; $x_{H d}=1$. The expected payoffs for giving or not giving extra teaching to a disadvantaged and high-ability student are $\Pi_{H d}^{T}=\mu z_{U d}-c(1-s)$ and $\Pi_{H d}^{N T}=\mu \eta_{H} z_{U d}$, respectively. This must be $\Pi_{H d}^{T} \geq \Pi_{H d}^{N T}$, that is $\mu z_{U d}-$ $c(1-s) \geq \mu \eta_{H} z_{U d}$, and therefore $\mu \geq c(1-s) / z_{U d}\left(1-\eta_{H}\right)$. The expected payoffs for giving or not giving extra teaching to a disadvantaged and lowability student are $\Pi_{L d}^{T}=z_{U d} \mu \eta_{L}-c(1-s)$ and $\Pi_{H d}^{N T}=0$, respectively. 
This must be $\Pi_{L d}^{T}=\Pi_{L d}^{N T}$, that is $z_{U d} \mu \eta_{L}-c(1-s)=0$, and therefore $z_{U d}=c(1-s) / \mu \eta_{L}$.

Job capacity. The total number of hired students ${ }^{20}$ is:

$$
\lambda\left(p_{a}+\eta_{L}\left(1-p_{a}\right)\right)+(1-\lambda)\left(p_{d}(1+\nu)\right) \frac{c(1-s)}{\mu \eta_{L}} \leq \Phi,
$$

thus job capacity implies

$$
z_{U d}=\min \left\{\frac{c(1-s)}{\mu \eta_{L}}, \frac{\Phi-\lambda\left(p_{a}+\eta_{L}\left(1-p_{a}\right)\right)}{(1-\lambda)\left(p_{d}(1+\nu)\right)}\right\} .
$$

Case 3. $p_{d}<p_{a}<\eta_{L} /\left(\nu+\eta_{L}\right)$

For advantaged students we refer to the proof (case 3) of Proposition 2. As $p_{d}<\eta_{L} /\left(\nu+\eta_{L}\right)$, the employer and school strategy for disadvantaged students does not change compared to the previous case.

Job capacity. The total number of hired students is:

$$
\frac{c}{\mu \eta_{L}}\left(\lambda p_{a}+(1-s)(1-\lambda) p_{d}\right)(1+\nu) \leq \Phi,
$$

thus job capacity implies

$$
z_{U a}=\min \left\{\frac{c}{\mu \eta_{L}}, \frac{\Phi}{\left(\lambda p_{a}+(1-s)(1-\lambda) p_{d}\right)(1+\nu)}\right\},
$$

and

$$
z_{U d}=\min \left\{\frac{c(1-s)}{\mu \eta_{L}}, \frac{\Phi-\lambda p_{a}(1+\nu) c / \mu \eta_{L}}{\left.(1-\lambda) p_{d}\right)(1+\nu)}\right\} .
$$

\footnotetext{
${ }^{20}$ Note that the number of disadvantaged and high-grade students in this equilibrium is $(1-\lambda)\left(p_{d}+\eta\left(1-p_{d}\right) x_{L d}\right)$ where $x_{L d}=p_{d} \nu /\left(1-p_{d}\right) \eta_{L}$, by substituting we obtain $(1-\lambda)\left(p_{d}+\eta\left(1-p_{d}\right) p_{d} \nu /\left(1-p_{d}\right) \eta_{L}\right)$, which can be simplified in $(1-\lambda)\left(p_{d}(1+\nu)\right)$.
} 


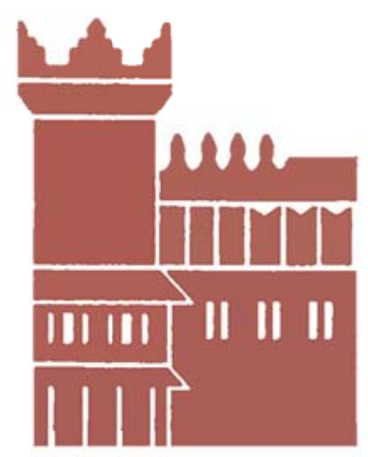

Alma Mater Studiorum - Università di Bologna DEPARTMENT OF ECONOMICS

Strada Maggiore 45

40125 Bologna - Italy

Tel. +39051 2092604

Fax +390512092664

http://www.dse.unibo.it 